\title{
Influence of Titanium Diboride Particle Size on Structure and Mechanical Properties of an Al-Mg Alloy
}

\author{
Anton P. Khrustalyov ${ }^{1, *(\mathbb{D}}$, Alexander A. Kozulin ${ }^{1}$, Ilya A. Zhukov ${ }^{1}$, Marina G. Khmeleva ${ }^{1}{ }^{(\mathbb{D}}$, \\ Alexander B. Vorozhtsov ${ }^{1}$, Dmitry Eskin ${ }^{1,2}$, Suwaree Chankitmunkong ${ }^{2,3}$, Vladimir V. Platov ${ }^{1}$ \\ and Sergey V. Vasilyev ${ }^{4}$ \\ 1 Faculty of Physics and Engineering, National Research Tomsk State University, 634050 Tomsk, Russia; \\ kzln2015@yandex.ru (A.A.K.); gofra930@gmail.com (I.A.Z.); khmelmg@gmail.com (M.G.K.); \\ abv1953@mail.ru (A.B.V.); vova.platov.85@mail.ru (V.V.P.); dmitry.eskin@brunel.ac.uk (D.E.) \\ 2 Brunel Centre for Advanced Solidification Technology, Brunel University London, Uxbridge, \\ Middlesex UB8 3PH, UK; suwaree.03@mail.kmutt.ac.th \\ 3 Department of Production Engineering, King Mongkut's University of Technology Thonburi, \\ Bangkok 10140, Thailand \\ 4 Joint-Stock Company "Scientific-production concern” Mechanical engineering, 125212 Moscow, Russia; \\ ecamo@mail.ru \\ * Correspondence: tofik0014@mail.ru; Tel.: +79-52-155-5568
}

Received: 7 August 2019; Accepted: 20 September 2019; Published: 23 September 2019

\begin{abstract}
In the present study, aluminum alloys of the Al-Mg system with titanium diboride particles of different size distribution were obtained. The introduction of particles in the alloy was carried out using master alloys obtained through self-propagating high-temperature synthesis (SHS) process. The master alloys consisted of the intermetallic matrix $\mathrm{Al}-\mathrm{Ti}$ with distributed $\mathrm{TiB}_{2}$ particles. The master alloys with $\mathrm{TiB}_{2}$ particles of different size distribution were introduced in the melt with simultaneous ultrasonic treatment, which allowed the grain refining of the aluminum alloy during subsequent solidification. It was found that the introduction of micro- and nanoparticles $\mathrm{TiB}_{2}$ increased the yield strength, tensile strength, and plasticity of as-cast aluminum alloys. After pass rolling the castings and subsequent annealing, the effect of the presence of particles on the increase of strength properties is much less felt, as compared with the initial alloy. The recrystallization of the structure after pass rolling and annealing was the major contributor to hardening that minimized the effect of dispersion hardening due to the low content of nanosized titanium diboride.
\end{abstract}

Keywords: aluminum alloy; titanium diboride; master alloy; structure; mechanical properties

\section{Introduction}

At present, a wrought AA5056 alloy is widely used in aircraft engineering, maritime transport, and pipeline design due to high corrosion resistance and good weldability by traditional methods [1,2]. The AA5056 alloy is mainly used as sheets. The highest mechanical properties of this alloy are achieved by dispersion hardening with the introduction of elements such as zirconium or scandium [3-5]. The main disadvantage of dispersion hardening is the high cost which leads to a significant increase in the cost of products. Under the production of the rolled metal, additional deformation treatment affects the formation of the internal structure of an alloy that directly influences the change in its mechanical properties. In addition to dispersion hardening and deformation, there are methods to obtain high physical and mechanical properties of aluminum alloys, such as the modification of 
the structure by grain refining during melt solidification and the hardening of the metal matrix by introducing submicron non-metallic particles [6-9].

To refine or modify the structure, a chemical inoculant is usually introduced into an aluminum alloy. Due to the close parameters of the crystal structure and specific size, inoculants can act as centers of heterogeneous nucleation upon undercooling the liquid metal during its solidification [10]. Titanium diboride $\left(\mathrm{TiB}_{2}\right)$ is the most widely used grain refiner for aluminum alloys. $\mathrm{TiB}_{2}$ modifier is introduced by the "ex-situ" method using Al-5Ti-1B master alloys [10-12] (containing $\mathrm{Al}_{3} \mathrm{Ti}$ and $\mathrm{TiB}_{2}$ particles in the aluminum matrix), or is synthesized by the "in-situ" method using $\mathrm{K}_{2} \mathrm{TiF}_{6}$ and $\mathrm{KBF}_{4}$ [13]. As shown by recent studies, titanium diboride particles are not sufficiently active centers of solidification by themselves and require the formation of a two-dimensional compound $\mathrm{Al}_{3} \mathrm{Ti}$ on their surface [10]. It has been shown in [14] that the optimal size of titanium diboride particles is from 1 to $5 \mu \mathrm{m}$ for their use as inoculants in aluminum alloys upon conventional cooling rates and corresponding levels of melt undercooling. At the same time, it is known that for dispersion hardening of aluminum alloys, involving the Orowan mechanism, it is necessary to use particles with size less than $500 \mathrm{~nm}$, such as aluminum oxide [15,16], silicon carbide [17], etc. These fine non-metallic particles become an obstacle for the moving dislocations in aluminum upon its deformation [18]. In this case, non-metallic particles should be uniformly distributed in the volume of the aluminum matrix, and have a good connection with the matrix which is retained during the dislocation motion. However, there are some problems with the introduction of particles into the metallic melt, related to their agglomeration and flotation due to poor wettability by the liquid metal. To solve these problems, ultrasonic (US) treatment can be used. US treatment allows for the degassing of the melt [19], improves the wettability and the distribution of nanoparticles [20] in the liquid volume. Master alloys with nanoparticle-reinforced aluminum matrix [16] are also used to improve the wettability of nanoparticles with the melt. Titanium diboride can be an effective obstacle to the motion of dislocations in aluminum due to its high hardness and stability [21]. Hence, the motivation for this study is the simultaneous use of titanium diboride particles for both the grain refinement and the dispersion hardening of the structure of aluminum alloys. This can be accomplished through the usage of the master alloys with a given chemical composition containing titanium diboride particles in a bimodal size distribution in nano- and micro-size ranges. For example, it has been shown in [22] that when modifying titanium diboride microparticles and aluminum oxide nanoparticles were introduced separately, the microstructure was refined and the aluminum matrix was reinforced, resulting in the increased strength and electrical conductivity.

One of the possible methods for obtaining the bimodal distribution of titanium diboride particles in a master alloy can be self-propagating high-temperature synthesis (SHS) [23]. In this case, titanium diboride particles in the master alloy are formed during combustion, and the size of titanium diboride particles and the phase composition of the matrix of obtained master alloys can be changed by controlling the process (speed, combustion temperature) of the initial powder system Al-Ti-B. Under the use of the exothermic reaction of stoichiometric ratios of titanium and boron at the production of the master alloys, the method specified can be considered as energy efficient since it does not require additional power sources to initiate and sustain the combustion.

Thus, the aim of this study is to investigate the effect of introducing master alloys containing titanium diboride particles on the structure and mechanical properties of aluminum alloys of the $\mathrm{Al}-\mathrm{Mg}$ system in the as-cast condition and after deformation.

\section{Materials and Methods}

\subsection{Master Alloys Production}

Master alloys (MA) obtained by SHS process from the initial powder mixture of aluminum, titanium, and boron were used for the introduction of titanium diboride particles into the aluminum melt. Morphology, dispersion, chemical composition of powder materials, equipment for obtaining of 
alloys, and the procedure of SHS testing are described in detail in [22,24]. Here we give briefly some essential data.

The exothermic reaction of the powder systems is characterized by the interaction of titanium and boron, based on the formation of the intermetallic phase $\mathrm{Ti}_{3} \mathrm{Al}$ :

$$
4 \mathrm{Ti}+2 \mathrm{~B}+\mathrm{Al}=\mathrm{TiB}_{2}+\mathrm{Ti}_{3} \mathrm{Al}+\mathrm{Q}
$$

The SHS process is used to obtain composites. Each individual powder particle can be represented schematically as follows. SEM images of the obtained SHS materials can be found elsewhere [22]. The master alloy contains uniformly distributed particles of titanium diboride in the Ti-Al matrix (see Figure 1).

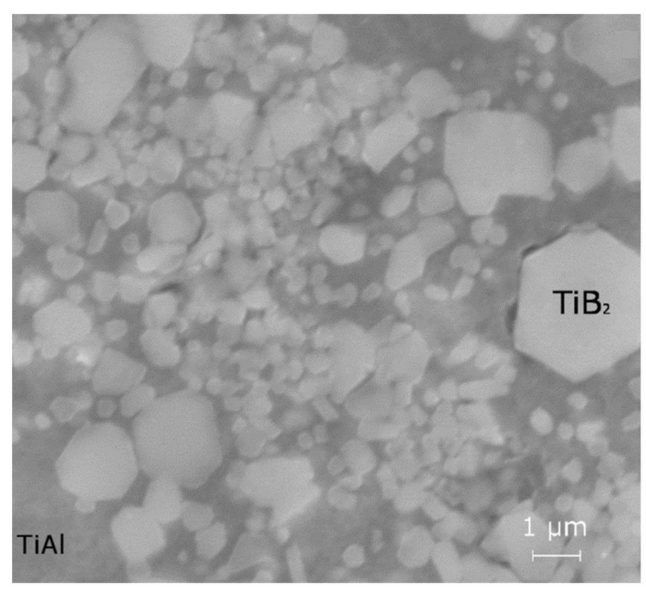

Figure 1. The microstructure of the master alloy [22]

The phase compositions of the obtained master alloys are listed in Table 1, and X-ray patterns are presented in Figures 2-4.

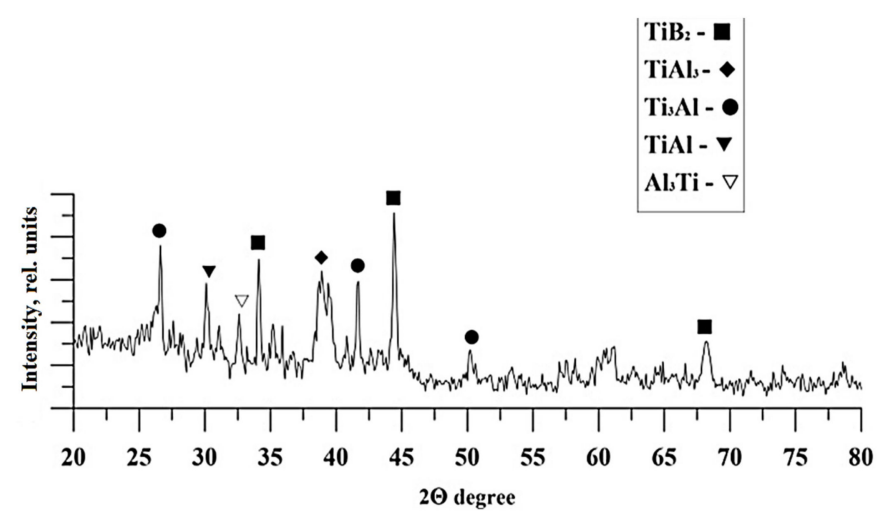

Figure 2. X-ray diffraction diagram of the MA1. 


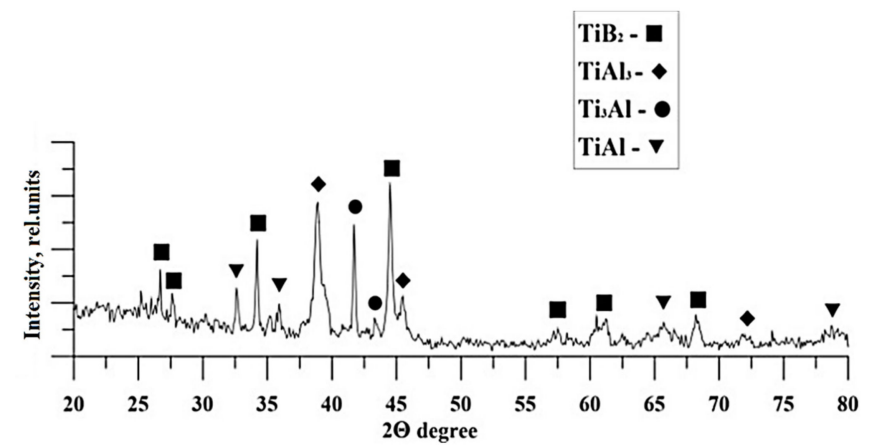

Figure 3. X-ray diffraction diagram of the MA2.

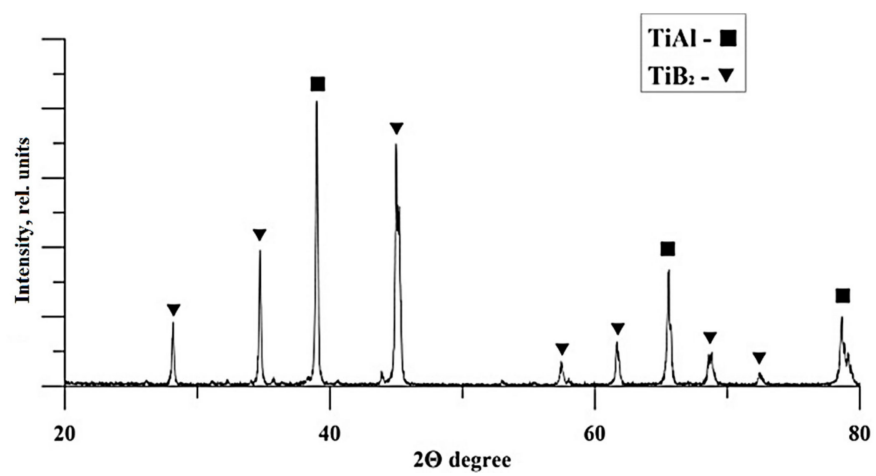

Figure 4. X-ray diffraction diagram of the MA3.

Table 1. Compositions of master alloys.

\begin{tabular}{cccc}
\hline Master-Alloy & Phase & Phase Content, wt $\%$ & Lattice Parameter, $\AA$ \\
\hline \multirow{2}{*}{1} & $\mathrm{TiB}_{2}$ & 30 & $\mathrm{a}=3.0296, \mathrm{c}=3.2260$ \\
\cline { 2 - 4 } & $\mathrm{Al}_{3} \mathrm{Ti}$ & 26 & $\mathrm{a}=4.0123$ \\
\cline { 2 - 4 } & $\mathrm{Ti}_{3} \mathrm{Al}$ & 9 & $\mathrm{a}=5.6683, \mathrm{c}=4.5854$ \\
\cline { 2 - 4 } & $\mathrm{TiAl}$ & 35 & $\mathrm{a}=4.0115$ \\
\hline \multirow{2}{*}{2} & $\mathrm{TiB}_{2}$ & 30 & $\mathrm{a}=3.0293, \mathrm{c}=3.2257$ \\
\cline { 2 - 4 } & $\mathrm{Al}_{3} \mathrm{Ti}$ & 40 & $\mathrm{a}=3.9484, \mathrm{c}=8.4989$ \\
\cline { 2 - 4 } & $\mathrm{Ti}_{3} \mathrm{Al}$ & 14 & $\mathrm{a}=5.6640, \mathrm{c}=4.6344$ \\
\cline { 2 - 4 } & $\mathrm{TiAl}$ & 16 & $\mathrm{a}=4.0278$ \\
\hline \multirow{2}{*}{3} & $\mathrm{TiAl}^{3}$ & 57 & $\mathrm{a}=4.0319$ \\
\cline { 2 - 4 } & $\mathrm{TiB}_{2}$ & 43 & \multicolumn{2}{c}{} \\
\hline
\end{tabular}

Changes in the lattice parameters of the components in the obtained master alloys were observed. This is due to the high temperature and flow rate of SHS, during which there is a distortion of the lattice and the change of lattice parameters. Due to the different composition of the initial components, the time and speed of the process change, which leads to different lattice parameters for the $\mathrm{TiB}_{2}, \mathrm{Al}_{3} \mathrm{Ti}$, $\mathrm{Ti}_{3} \mathrm{Al}$, and $\mathrm{TiAl}$ phases in the master alloys.

The histograms of the particle size distribution for titanium diboride particles are presented in Figure 5. The particle is initially composite. After synthesis, the obtained materials were crushed and milled into powder. The particles of the obtained powder material consisted of an intermetallic matrix of type (Ti-Al) and $\mathrm{TiB}_{2}$ particles were uniformly distributed in it. The matrix was then etched with a solution of $\mathrm{H} 2 \mathrm{O}-20 \% \mathrm{HCl}$ for $72 \mathrm{~h}$. Further $\mathrm{TiB}_{2}$ particles were mixed with aluminum powder. The resulting mixtures were pressed into tablets with a diameter of $23 \mathrm{~mm}$. The resulting tablets were sintered in a vacuum furnace for $1 \mathrm{~h}$ at a temperature of $600{ }^{\circ} \mathrm{C}$. 


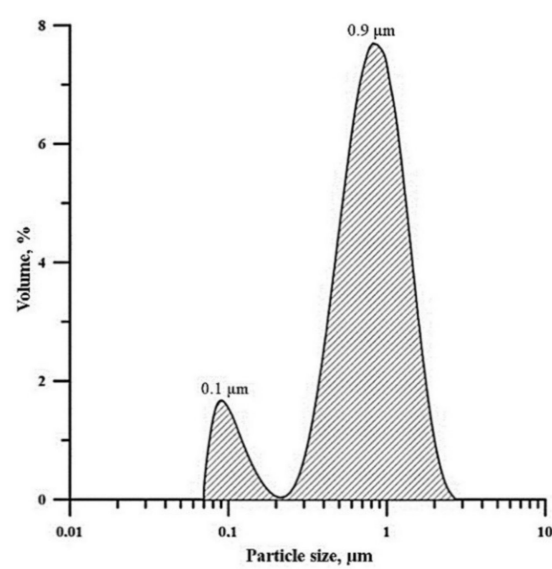

(a)

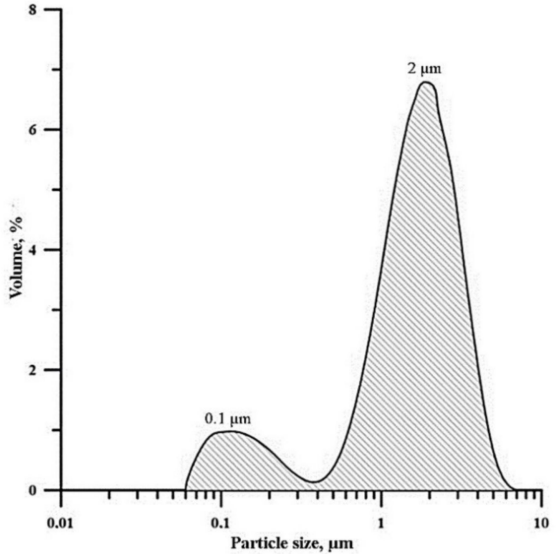

(b)

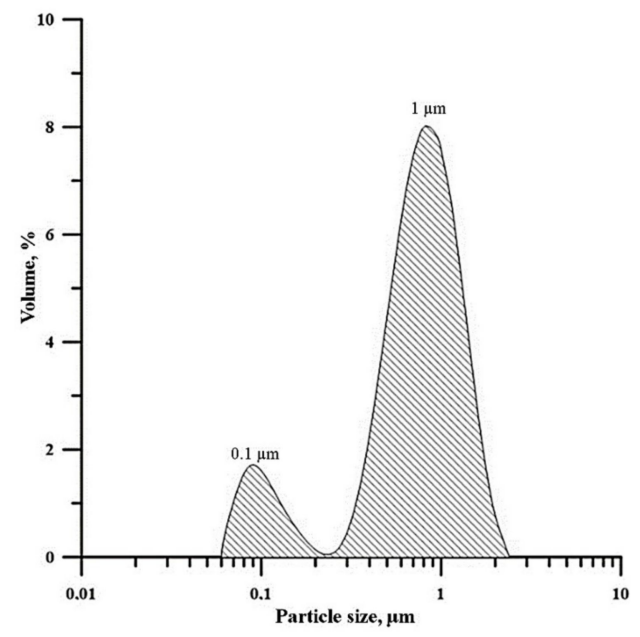

(c)

Figure 5. Histograms of the particle distribution in master alloys MA1 (a), MA2 (b), and MA3 (c) as determined in ANALYSETTE 22 MicroTec plus.

\subsection{Obtaining the Alloys}

An aluminum alloy AA5056 (91.9-94.68 $\mathrm{wt} \% \mathrm{Al}, 4.8-5.8 \mathrm{wt} \% \mathrm{Mg}$ ) was used as the starting material. A total of $1 \mathrm{~kg}$ of the AA5056 alloy was placed in a clay-graphite crucible, melted in an electric muffle furnace at a temperature of $780^{\circ} \mathrm{C}$, and kept for $2 \mathrm{~h}$. Then the crucible was removed from the furnace by using a holding device, and a master alloy was introduced into the melt with simultaneous ultrasonic treatment at a temperature of $730^{\circ} \mathrm{C}$. Ultrasonic processing was carried out using a magnetostrictive water-cooled transducer at a power of $4.1 \mathrm{~kW}$ and a frequency of $17.6 \mathrm{kHz}$. After complete dissolution of the master alloys ultrasonic treatment continued for a further $2 \mathrm{~min}$. The liquid metal was then placed in the furnace for $30 \mathrm{~min}$, and then ultrasonic treatment was carried out for another $2 \mathrm{~min}$. The melt was poured into a chill mold at a temperature of $720{ }^{\circ} \mathrm{C}$. In addition, AA5056 + MA1 alloys without ultrasonic treatment and an AA5056 alloy with ultrasonic treatment were obtained as references. The data of obtained alloys are given in Table 2. 
Table 2. A list of obtained alloys.

\begin{tabular}{ccccc}
\hline Alloy Matrix & $\begin{array}{c}\text { Ultrasonic } \\
\text { Treatment }\end{array}$ & Master Alloy & $\begin{array}{c}\mathrm{TiB}_{\mathbf{2}} \text { Particle Quantity } \\
\text { in a Master Alloy, } \%\end{array}$ & $\begin{array}{c}\mathrm{TiB}_{\mathbf{2}} \text { Particle Quantity } \\
\text { in 1 kg of an Alloy }\end{array}$ \\
\hline AA5056 & + & - & - & - \\
AA5056 & - & MA1 & 30 & $4 \times 10^{20} \pm 6 \times 10^{10}$ \\
AA5056 & + & MA1 & 30 & $4 \times 10^{20} \pm 6 \times 10^{10}$ \\
AA5056 & + & MA2 & 32 & $4 \times 10^{20} \pm 6 \times 10^{10}$ \\
AA5056 & + & MA3 & 43 & $4.5 \times 10^{20} \pm 7.3 \times 10^{10}$ \\
\hline
\end{tabular}

Particle quantity for MA1 was 17 vol.\% nano-83 vol.\% micro, for MA2 14 vol.\% nano-86 vol.\% micro, for MA3 18\% nano-82\% micro.

\subsection{Rolling Technique}

Prismatic samples with a size of $11 \times 17 \times 40 \mathrm{~mm}^{3}$ were machined from the resulting castings. For rolling, a rolling mill with a roll diameter of $80 \mathrm{~mm}$ and a rotation speed of $24 \mathrm{rpm}$ was used. Rolling of the aluminum alloys was carried out after preheating the samples in a muffle furnace at 300 ${ }^{\circ} \mathrm{C}$ for $30 \mathrm{~min}$. Rolling was carried out to change the sample thickness from 11 to $2 \mathrm{~mm}$ in several cycles with intermediate heating for $15 \mathrm{~min}$ at $300^{\circ} \mathrm{C}$. Each cycle was divided into seven reversible passes. A single-pass rolling provided compression up to $4 \%$. The number of passes per cycle was selected experimentally based on the sample temperature during cooling. Rolling at lower temperatures leads to the appearance of defects within the sample volume and the main crack growth during subsequent working cycles regardless of the temperature and deformation modes applied.

\subsection{Methods of Analysis of Initial Materials and Alloys}

The structures of the obtained materials were investigated through optical microscopy, Olympus GX71 (Olympus Scientific Solutions Americas, Waltham, MA, USA). Samples were subjected to preliminary mechanical polishing, electrolytical etching, and anodization. The electrochemical oxidation of the metallographic specimen surface in a $5 \%$ solution of hydrofluoric acid $\left(\mathrm{HBF}_{4}\right)$ at a voltage of $20 \mathrm{~V}$ and a current of $2 \mathrm{~A}$ was carried out to identify grain boundaries. Grain sizes were determined by a random linear intercept method from electronic images of the structure.

The phase composition and the structure of master alloys were performed using X-ray phase and X-ray diffraction methods. X-ray diffraction analysis of master alloys was performed using a SHIMADZU XRD 6000 diffractometer (Shimadzu, Tsukinowa, Japan). The phase composition analysis was carried out using PDF 4+ databases, as well as the POWDER CELL 2.4 full-profile analysis program. The particle dispersion was researched on ANALYSETTE 22 MicroTec plus (FRITSCH, Gamburg, Germany) by laser diffraction. Particle dispersion was measured in water. Mechanical tests were performed on a universal testing machine, Instron 3369 (Instron European Headquarters, High Wycombe, UK), at the speed of $0.2 \mathrm{~mm} / \mathrm{min}$. The samples were cut from castings and rolling products using electrical discharge machining (Scientific Industrial Corporation DELTA-TEST, Fryazino, Moscow Region, Russia). The samples are shaped as flat double-sided blades with a thickness of $2 \mathrm{~mm}$, the ratio of the width of the working and holding parts is greater or equal to 1.5. Tests were conducted according to ASTM B557-15.

\section{Results}

The optical micrographs of the microstructures of the AA5056-based alloys are presented in Figure 6. 


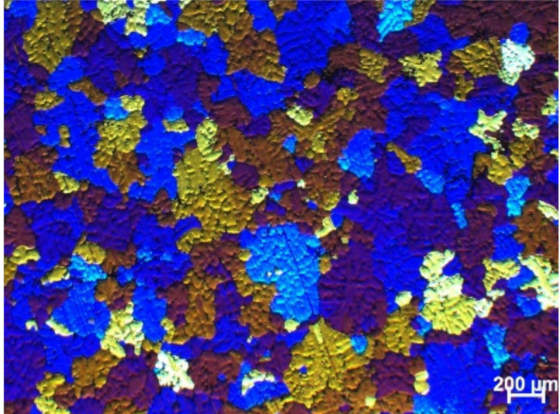

$<\mathrm{d}>=205 \pm 30 \mu \mathrm{m}$

(a)

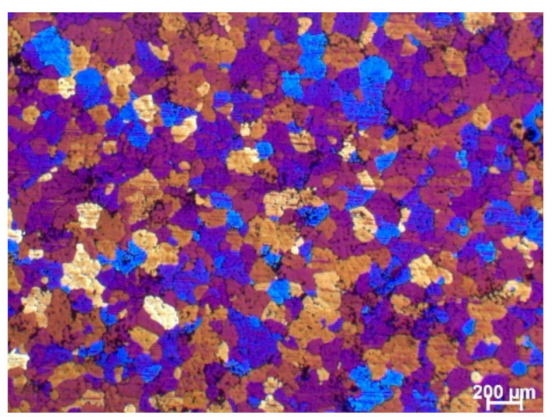

$<\mathrm{d}>=163 \pm 18 \mu \mathrm{m}$

(c)

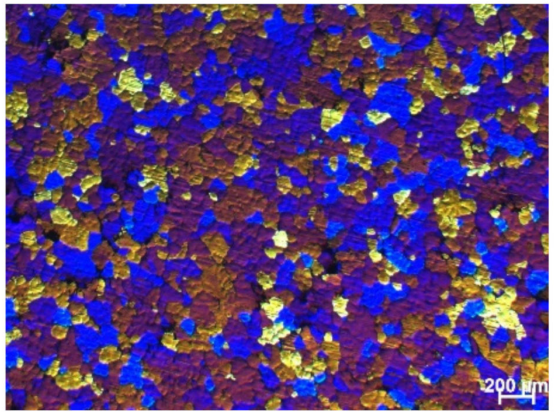

$<\mathrm{d}>=164 \pm 12 \mu \mathrm{m}$

(b)

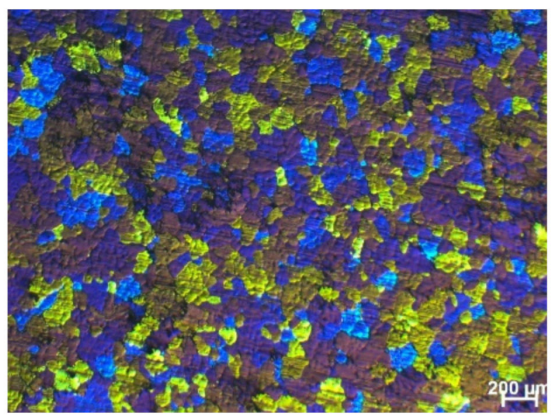

$<\mathrm{d}>=158 \pm 8 \mu \mathrm{m}$

(d)

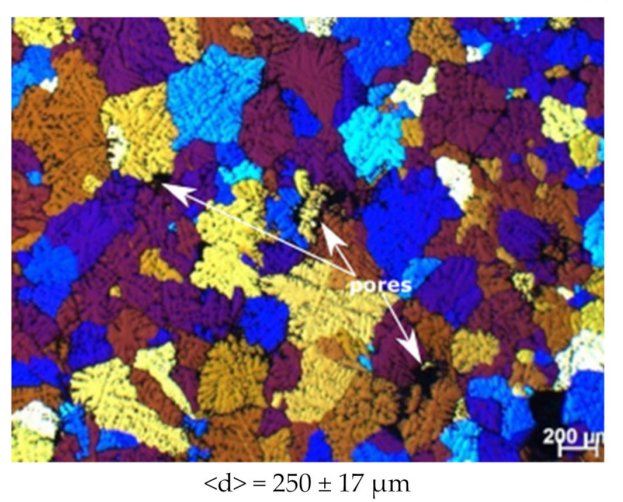

(e)

Figure 6. Microstructure of obtained alloys: AA5056 reference ultrasonic (US) (a), AA5056 + MA1 US (b), AA5056 + MA2 US (c), AA5056 + MA3 US (d), AA5056 + MA1 without US (e).

The average grain size of the initial alloy AA5056 after ultrasonic treatment (AA5056 reference US) was $205 \pm 30 \mu \mathrm{m}$ (Figure 6a). Ultrasonic treatment of the alloy AA5056 allows obtaining the microstructure with equiaxed grains. The introduction of the master alloy MA1 with ultrasonic treatment (AA5056 + MA1 US) reduced significantly the average grain size of the alloy AA5056 from $205 \pm 30$ to $164 \pm 12 \mu \mathrm{m}$ (Figure $6 \mathrm{~b}$ ). The addition of the master alloy MA2 (AA5056 + MA2 US) had a similar effect, reducing the average grain size to $163 \pm 18 \mu \mathrm{m}$ (Figure 6c), while the master alloy MA3 (AA5056 + MA3 US) reduced the grain size to $158 \pm 8 \mu \mathrm{m}$ (Figure 6d). Grain distribution histograms of the AA5056-based alloys are presented in Figure 7. At the same time, there are grains with size larger than $250 \mu \mathrm{m}$ in the structure of the alloy AA5056 obtained without US (AA5056 + MA1 without US). The use of the master alloy without ultrasonic processing did not allow for introducing particles and distributing them in the volume of the ingot. Since the alloy had non-uniform distribution of particles, the grain of the alloy AA5056 cannot be refined, and its average size was $250 \pm 17 \mu \mathrm{m}$ and large pores were observed in the structure (see black inclusions in Figure 6e). 


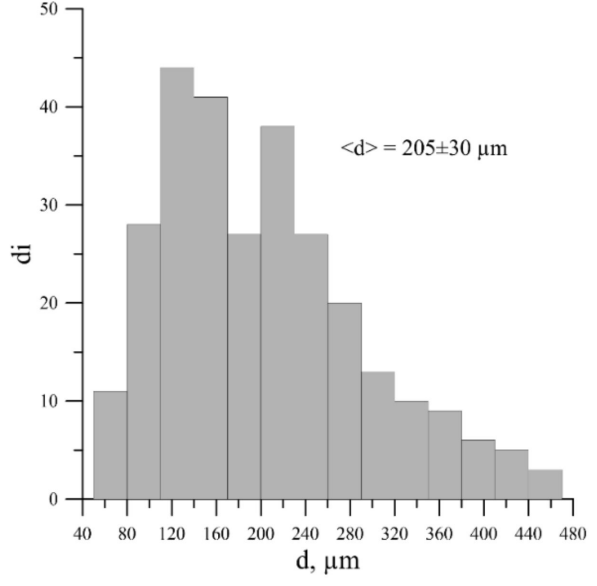

(a)

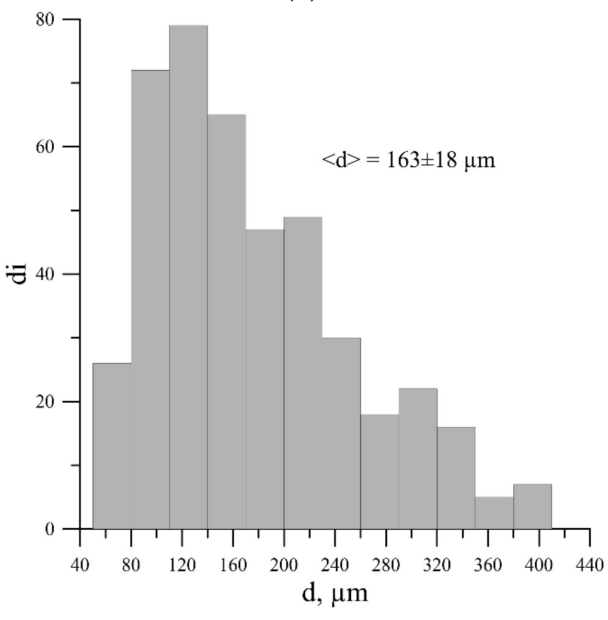

(c)

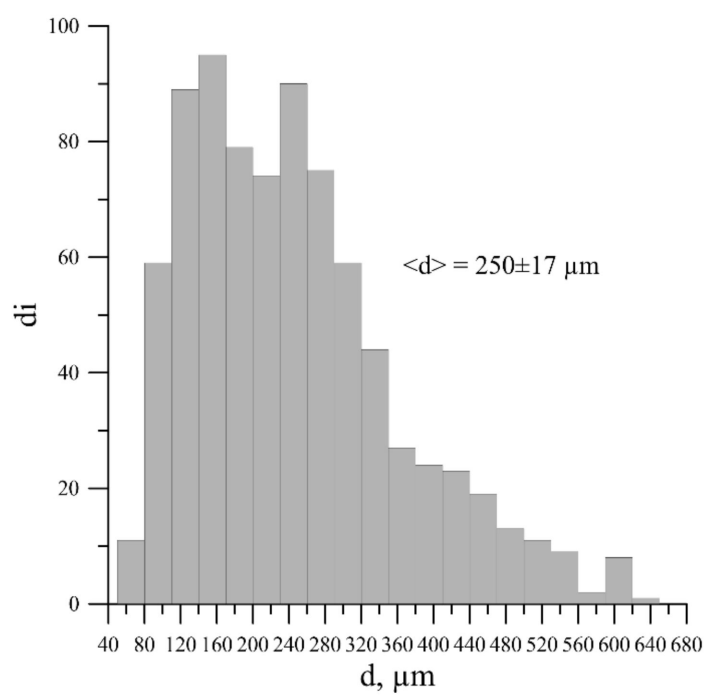

(e)

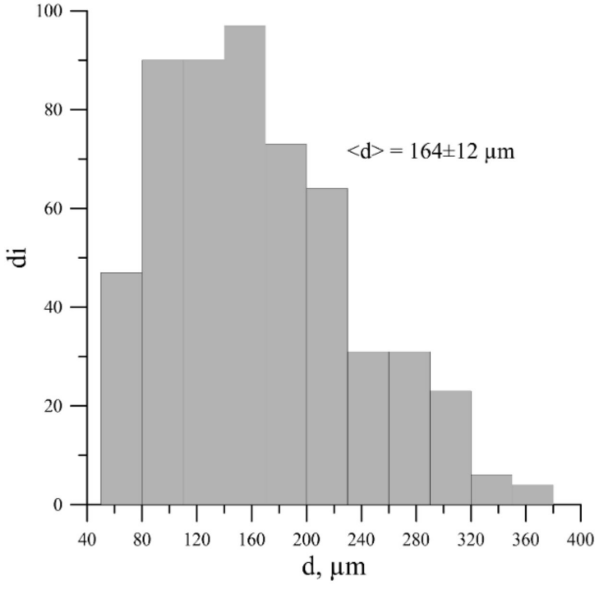

(b)

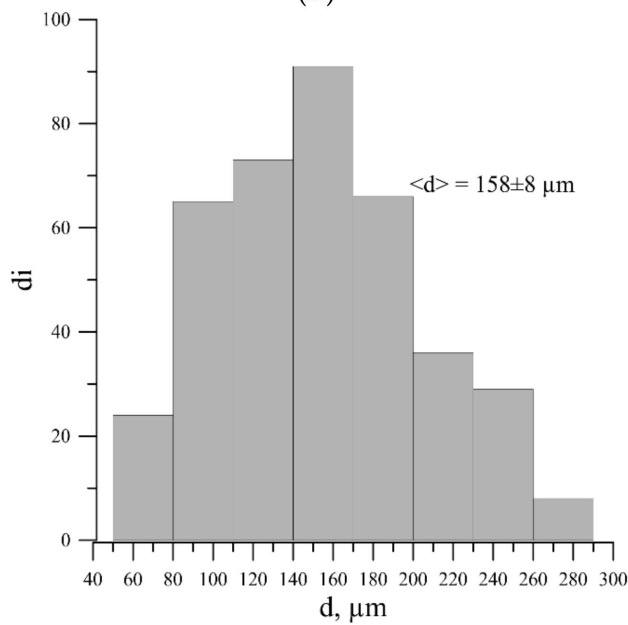

(d) 


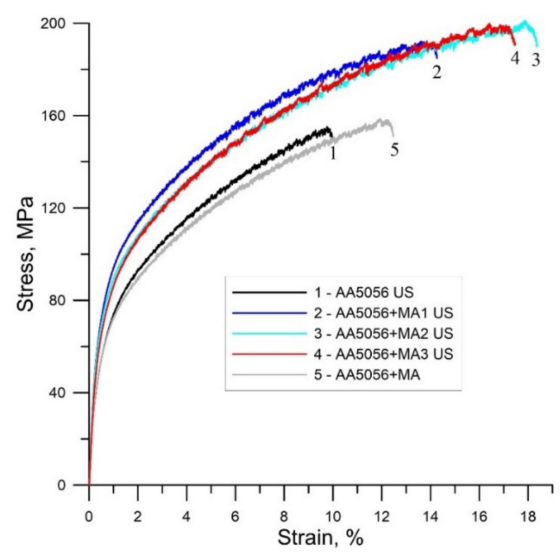

Figure 8. Diagrams of uniaxial tension of AA5056-based cast alloys.

The analysis of the diagrams allowed us to estimate the yield strength, tensile strength, and elongation of the cast AA5056 reference US alloy as $57 \mathrm{MPa}, 155 \mathrm{MPa}$, and $11.5 \%$, respectively (Table 3). After addition of MA1 (AA5056 + MA1 US), its mechanical properties increased significantly: yield strength from 57 to $74 \mathrm{MPa}$, tensile strength from 155 to $192 \mathrm{MPa}$, and elongation from $11.5 \%$ to $14.5 \%$ (Table 3). The introduction of particles from MA2 (AA5056 + MA2 US) also led to the increase in yield strength from 57 to $71 \mathrm{MPa}$, tensile strength from 155 to $201 \mathrm{MPa}$, and elongation from $11.5 \%$ to $18.8 \%$ (Table 3). Finally, the addition of MA3 (AA5056 + MA3 US) did not change the yield strength which amounted $69 \mathrm{MPa}$, increase tensile strength from 155 to $200 \mathrm{MPa}$, and elongation from $11.5 \%$ to $17.8 \%$ (Table 3). Without ultrasonic processing, the addition of MA1 (AA5056 + MA1 without US) into the base alloy decreased the yield strength from 57 to $53 \mathrm{MPa}$ with negligible change in tensile strength from 155 to $159 \mathrm{MPa}$, and elongation from $11.5 \%$ to $12.9 \%$.

Table 3. Mechanical properties of as-cast AA5056-based alloys.

\begin{tabular}{cccc}
\hline Alloy & $\boldsymbol{\sigma}_{\mathbf{0 . 2}}, \mathbf{M P a}$ & $\boldsymbol{\sigma}_{\mathbf{B}}, \mathbf{M P a}$ & $\boldsymbol{\delta}, \boldsymbol{\%}$ \\
\hline AA5056 US & $57 \pm 4$ & $155 \pm 11$ & $11.5 \pm 0.8$ \\
AA5056 US + MA1 & $74 \pm 7$ & $192 \pm 14$ & $14.5 \pm 0.4$ \\
AA5056 US + MA2 & $71 \pm 6$ & $201 \pm 12$ & $18.8 \pm 0.6$ \\
AA5056 US + MA3 & $69 \pm 8$ & $200 \pm 10$ & $17.8 \pm 0.5$ \\
\hline
\end{tabular}

The yield strength increases up to $345 \mathrm{MPa}$ under the subsequent deformation by rolling of workpieces obtained from castings of the alloy AA5056 US, and it decreased to 328, 304, $330 \mathrm{MPa}$ with the additions of master alloys MA1 (AA5056 US + MA1), MA2 (AA5056 US + MA2), and MA3 (AA5056 US + MA3), respectively (Table 4).

Table 4. The mechanical properties of deformed AA5056-based alloys.

\begin{tabular}{|c|c|c|c|}
\hline Alloy & $\sigma_{0.2}, \mathrm{MPa}$ & $\sigma_{\mathrm{B}}, \mathrm{MPa}$ & $\delta, \%$ \\
\hline \multicolumn{4}{|c|}{ Pass rolling } \\
\hline AA5056 US & $345 \pm 11$ & $369 \pm 16$ & $9.6 \pm 0.3$ \\
\hline AA5056 US + MA1 & $328 \pm 13$ & $365 \pm 17$ & $12.3 \pm 0.4$ \\
\hline AA5056 US + MA2 & $304 \pm 16$ & $349 \pm 19$ & $8.4 \pm 0.2$ \\
\hline AA5056 US + MA3 & $330 \pm 12$ & $350 \pm 17$ & $10 \pm 0.3$ \\
\hline \multicolumn{4}{|c|}{ Pass rolling + annealing } \\
\hline AA5056 US & $217 \pm 9$ & $311 \pm 11$ & $22.2 \pm 0.3$ \\
\hline AA5056 US + MA1 & $189 \pm 10$ & $309 \pm 13$ & $17.9 \pm 0.1$ \\
\hline AA5056 US + MA2 & $197 \pm 7$ & $286 \pm 10$ & $18.9 \pm 0.2$ \\
\hline AA5056 US + MA3 & $226 \pm 8$ & $316 \pm 12$ & $22.4 \pm 0.1$ \\
\hline
\end{tabular}


The introduction of MA1 (AA5056 US + MA1) led to an increase in the elongation from $9.6 \%$ to $12.3 \%$, but the strength did not change and equaled $365 \mathrm{MPa}$ (Table 4, Figure 9). The addition of MA2 (AA5056 US + MA2) reduced the elongation to $8.4 \%$ and the strength, from 369 to $349 \mathrm{MPa}$ (Table 4, Figure 9). The introduction of MA3 (AA5056 US + MA3) did not reduce the elongation but decreased the tensile strength from 369 to $350 \mathrm{MPa}$.

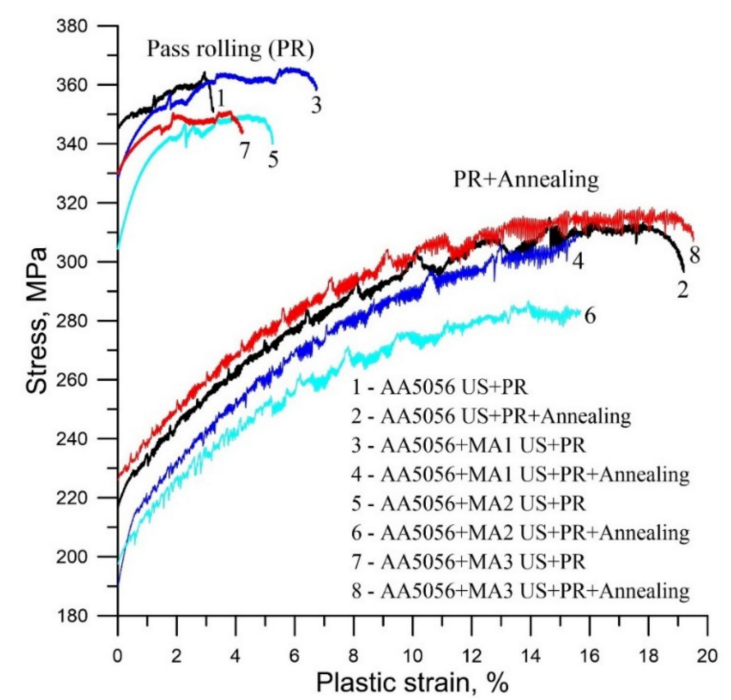

Figure 9. Stress-strain diagrams of aluminum alloys with master alloy additions MA1-MA3 after pass rolling and annealing.

After annealing, the yield strength, tensile strength, and elongation of the AA5056 US alloy were $217 \mathrm{MPa}, 311 \mathrm{MPa}$ and 22.2\%, respectively. The additions of MA1 (AA5056 US + MA1) or MA2 (AA5056 US + MA2) did not increase mechanical properties after pass rolling and annealing (see Table 4 and Figure 9). The introduction of MA3 (AA5056 US + MA3) did not reduce the mechanical properties (yield strength, tensile strength, and plasticity: $226 \mathrm{MPa}, 316 \mathrm{MPa}$, and $22.4 \%$, respectively).

\section{Discussion}

The inhomogeneity in the alloy grain structure with the master alloy MA2 (manifested by a large scatter of the results, see Figure 7c) may be related to the average particle sizes in the master alloys (Figure 1a,b). In the MA1 master alloy the size of most particles is $0.9 \mu \mathrm{m}$, while in the MA2 it is $2 \mu \mathrm{m}$, that leads to a half decrease in the number of potential solidification centers if we assume that this size should be around $1 \mu \mathrm{m}$. This effect is confirmed by introducing the MA3 master alloy into the AA5056 alloy, where the average particle size was $1 \mu \mathrm{m}$ (Figure $5 \mathrm{~d}$ ), and a more homogenous microstructure (see Figure 7c) was obtained as compared to the AA5056 US + MA2. A slightly better grain refinement effect by the MA3 master alloy may also be due to a higher concentration of particles per $1 \mathrm{~kg}$ of the alloy, which was $4.5 \times 10^{20}$ compared to $4 \times 10^{20}$ for the MA1 and MA2 master alloys (Table 2). The number of large particles in MA3 was $3.69 \times 10^{20}$ compared with $3.44 \times 10^{20}$ for MA2. The data obtained indicate that titanium diboride microparticles contained in the master alloys allowed the grain refinement of the AA5056 aluminum alloy.

The contribution to an increase of mechanical characteristics of the alloy with the master alloy additions may be due to the alloy grain size reduction (the Hall-Petch law) according to Equation (1).

$$
\sigma_{G R}=k_{y}\left(D^{-\frac{1}{2}}-D_{0}^{\frac{1}{2}}\right)
$$

where $k_{y}$ is the Hall-Petch parameter (68 MPa), $D$ is the grain size with a master alloy, $D_{0}$ is the grain size without a master alloy. These contributions can be estimated as 9.6-9.7 for the tested MA additions. 
An additional contribution to an increase in mechanical properties is made by hardening the metal matrix of the AA5056 aluminum alloy with titanium diboride nanoparticles $(0.1 \mu \mathrm{m})$ by the Orowan mechanism.

Titanium diboride nanoparticles can also provide load redistribution in the matrix, whose contribution according to Equation (2) is $8.4 \mathrm{MPa}$.

$$
\sigma_{\text {load }}=0.5 V_{p} \sigma_{m}
$$

where $V_{p}$ is the volume content of particles, $\sigma_{m}$ is the matrix yield strength.

The simultaneous increase in the yield strength, strength, and plasticity can be associated with the load redistribution in the matrix due to the introduction and distribution of nanoparticles, as previously suggested in $[16,25]$.

Lower mechanical characteristics of the deformed alloys with titanium diboride particles in relation to the base AA5056 US alloy without particles can be associated with a decrease in the contribution according to the Hall-Petch law, since the deformation treatment allows one to significantly refine grains of aluminum alloys $[9,26]$. To determine the effect of particles on the mechanical properties and exclude the internal stresses in the matrix, annealing of the aluminum alloy samples obtained was performed. After annealing, there was a decrease in the mechanical properties of the aluminum alloys with the MA1 and MA2 master alloys $\left(4 \times 10^{20}\right)$. The lower characteristics of the alloy with MA2 can be associated with a smaller amount of titanium diboride nanoparticles about $14 \mathrm{vol} \%$ compared with the MA1 master alloy of 17 vol. $\%$. A larger number of titanium diboride particles $\left(4.5 \times 10^{20}\right)$ in the MA3 master alloy did not reduce the mechanical characteristics of the alloy, providing additional dispersion hardening. A lower amount of titanium diboride nanoparticles did not, apparently, allow one to sufficiently strengthen the aluminum matrix after pass rolling with majority of particles redistributed to the grain boundaries (Figure 10a).

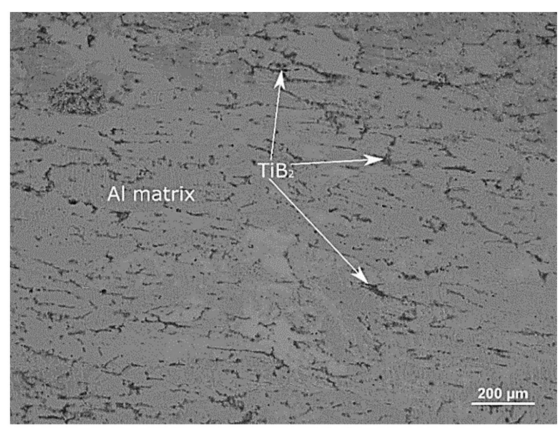

(a)

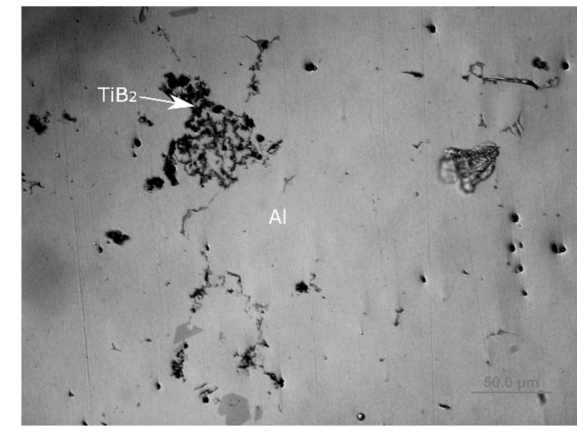

(b)

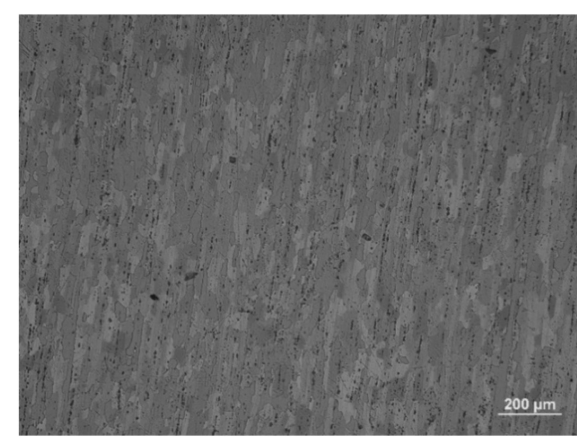

(c)

Figure 10. Microstructure of the AA5056 + MA3 US alloy after pass rolling (a) and cast AA5056 + MA3 US (b), AA5056 US (c). 
According to optical microscopy data the cast AA5056 + MA3 US alloy (Figure 10b) demonstrates separate agglomerates of particles, but their number was insignificant relative to the total area of the surface studied. The deformation significantly increases the amount of titanium diboride particles and agglomerates at grain boundaries of the AA5056 + MA3 US alloy due to the transfer of the agglomerates and individual particles from the bulk volume of the grain to the boundaries. Apparently, the selected number of deformation cycles was too large for treating an alloy with titanium diboride particles of different sizes. During the deformation of the AA5056 + MA1 US and AA5056 + MA2 US alloys, the number of cycles was five, therefore, an estimated number of $0.8 \times 10^{20}$ particles of titanium diboride might move to the grain boundary during each rolling pass. The uniformity of particle motion from the volume to the grain boundary requires additional evaluation on alloys with an intermediate number of cycles. For the given number of rolling passes, part of $\mathrm{TiB}_{2}$ particles in the AA5056 + MA3 US alloy can be preserved inside the grains, but those would end up at the grain boundaries as well upon further deformation. It may be suggested that a reduction in the number of rolling cycles will allow the particles to remain in grain volume, and the effect of grain refinement and reinforcement on the mechanical properties of an AA5056 alloy can be retained after deformation.

\section{Conclusions}

It was found that the introduction of bi-modal sized titanium diboride particles $\left(4-4.5 \times 10^{20}\right)$ allows one to refine the grain structure of the cast aluminum alloy AA5056 from 205 to $158 \mu \mathrm{m}$, thereby increasing its yield strength, tensile strength, and ductility from 57 to $71 \mathrm{MPa}$, from 155 to $201 \mathrm{MPa}$, and from $11.5 \%$ to $18.8 \%$, respectively. The greatest effect of the structure refinement is achieved by using alloys containing titanium diboride microparticles with a size of $1 \mu \mathrm{m}$. Nanoparticles present in bi-modal master alloys provide for additional hardening. After deformation the amount of titanium diboride nanoparticles is not enough for the dispersion hardening of the aluminum matrix and increasing the yield strength, tensile strength, and ductility of the AA5056 alloy after pass rolling, mostly due to their redistribution to grain boundaries. This effect can be controlled by the numbers of rolling passes.

Author Contributions: Conceptualization, I.A.Z. and A.P.K.; methodology, D.E., A.A.K., S.C. and S.V.V.; software, M.G.K.; A.P.K. and V.V.P.; resources, A.B.V. and D.E.; visualization, A.P.K. and A.A.K.; supervision, A.B.V. and D.E.

Funding: Russian Science Foundation: 17-13-01252; Council on grants of the President of the Russian Federation: 14.Y30.17.837-MK; EPSRC: EP/R011001/1, EP/R011044/1, EP/R011095/1; The Research and Researchers for Industry (RRi) under the Thailand Research Fund (TRF).

Acknowledgments: The research was performed with the financial support of Grant of Russian Science Foundation (Project No. 17-13-01252). Z.I.A. thank financial support of Presidential Grant MK-837.2017.8, contract number 14.Y30.17.837-MK in part of the work on the production of master alloys for aluminum alloys with $\mathrm{TiB}_{2}$ different size distributions. D.E and S.C. thank financial support of EPSRC grant UltraMelt2 (EP/R011001/1, EP/R011044/1 and EP/R011095/1) and The Research and Researchers for Industry (RRi) under the Thailand Research Fund (TRF).

Conflicts of Interest: The authors declare no conflict of interest.

\section{References}

1. Kawazoe, M.; Shibata, T.; Mukai, T.; Higashi, K. Elevated temperature mechanical properties of A 5056 Al-Mg alloy processed by equal-channel-angular-extrusion. Scr. Mater. 1997, 36, 699-705. [CrossRef]

2. Jones, R.H. The influence of hydrogen on the stress-corrosion cracking of low-strength Al-Mg alloys. JOM 2003, 55, 42-46. [CrossRef]

3. Lee, S.; Utsunomiya, A.; Akamatsu, H.; Neishi, K.; Furukawa, M.; Horita, Z.; Langdon, T.G. Influence of scandium and zirconium on grain stability and superplastic ductilities in ultrafine-grained Al-Mg alloys. Acta Mater. 2002, 50, 553-564. [CrossRef]

4. Filatov, Y.A.; Yelagin, V.I.; Zakharov, V.V. New Al-Mg-Sc alloys. Mater. Sci. Eng. A 2000, 280, 97-101. [CrossRef]

5. Ahmad, Z. The properties and application of scandium-reinforced aluminum. JOM 2003, 55, 35-39. [CrossRef] 
6. Yan, S.J.; Dai, S.L.; Zhang, X.Y.; Yang, C.; Hong, Q.H.; Chen, J.Z.; Lin, Z.M. Investigating aluminum alloy reinforced by graphene nanoflakes. Mater. Sci. Eng. A 2014, 612, 440-444. [CrossRef]

7. Vorozhtsov, S.; Minkov, L.; Dammer, V.; Khrustalyov, A.; Zhukov, I.; Promakhov, V.; Vorozhtsov, A.; Khmeleva, M. Ex situ introduction and distribution of nonmetallic particles in aluminum melt: Modeling and experiment. JOM 2017, 69, 2653-2657. [CrossRef]

8. Li, B.; Zhang, Z.; Shen, Y.; Hu, W.; Luo, L. Dissimilar friction stir welding of Ti-6Al-4V alloy and aluminum alloy employing a modified butt joint configuration: Influences of process variables on the weld interfaces and tensile properties. Mater. Des. 2014, 53, 838-848. [CrossRef]

9. Zhukov, I.; Promakhov, V.; Vorozhtsov, S.; Kozulin, A.; Khrustalyov, A.; Vorozhtsov, A. Influence of Dispersion Hardening and Severe Plastic Deformation on Structure, Strength and Ductility Behavior of an AA6082 Aluminum Alloy. JOM 2018, 70, 2731-2738. [CrossRef]

10. Fan, Z.; Wang, Y.; Zhang, Y.; Qin, T.; Zhou, X.R.; Thompson, G.E.; Pennycook, T.; Hashimoto, T. Grain refining mechanism in the Al/Al-Ti-B system. Acta Mater. 2015, 84, 292-304. [CrossRef]

11. Kotadia, H.R.; Qian, M.; Eskin, D.G.; Das, A. On the microstructural refinement in commercial purity $\mathrm{Al}$ and Al-10 wt \% Cu alloy under ultrasonication during solidification. Mater. Des. 2017, 132, 266-274. [CrossRef]

12. Li, Y.; Bai, Q.L.; Liu, J.C.; Li, H.X.; Du, Q.; Zhang, J.S.; Zhuang, L.Z. The influences of grain size and morphology on the hot tearing susceptibility, contraction, and load behaviors of AA7050 alloy inoculated with Al-5Ti-1B master alloy. Metal. Mater. Trans. A 2016, 47, 4024-4037. [CrossRef]

13. Mahamani, A.; Jayasree, A.; Mounika, K.; Reddi, K.; Sakthivelan, N. Evaluation of mechanical properties of AA6061-TiB2/ZrB2 in-situ metal matrix composites fabricated by K2TiF6-KBF4-K2ZrF6 reaction system. Int. J. Microstruct. Mater. Prop. 2015, 10, 185-200.

14. Greer, A.L.; Bunn, A.M.; Tronche, A.; Evans, P.V.; Bristow, D.J. Modelling of inoculation of metallic melts: Application to grain refinement of aluminium by Al-Ti-B. Acta Mater. 2000, 48, 2823-2835. [CrossRef]

15. Ezatpour, H.R.; Torabi Parizi, M.; Sajjadi, S.A.; Ebrahimi, G.R.; Chaichi, A. Microstructure, mechanical analysis and optimal selection of 7075 aluminum alloy based composite reinforced with alumina nanoparticles. Mater. Chem. Phys. 2016, 178, 119-127. [CrossRef]

16. Vorozhtsov, S.A.; Eskin, D.G.; Tamayo, J.; Vorozhtsov, A.B.; Promakhov, V.V.; Averin, A.A.; Khrustalyov, A.P. The application of external fields to the manufacturing of novel dense composite master alloys and aluminum-based nanocomposites. Metal. Mater. Trans. A 2015, 46, 2870-2875. [CrossRef]

17. Mousavian, R.T.; Khosroshahi, R.A.; Yazdani, S.; Brabazon, D.; Boostani, A.F. Fabrication of aluminum matrix composites reinforced with nano-to micrometer-sized SiC particles. Mater. Des. 2016, 89, 58-70. [CrossRef]

18. Liu, H.; Gao, Y.; Qi, L.; Wang, Y.; Nie, J.F. Phase-field simulation of Orowan strengthening by coherent precipitate plates in an aluminum alloy. Metal. Mater. Trans. A 2015, 46, 3287-3301. [CrossRef]

19. Eskin, D.G.; Al-Helal, K.; Tzanakis, I. Application of a plate sonotrode to ultrasonic degassing of aluminum melt: Acoustic measurements and feasibility study. J. Mater. Proc. Technol. 2015, 222, 148-154. [CrossRef]

20. Xuan, Y.; Nastac, L. The role of ultrasonic cavitation in refining the microstructure of aluminum based nanocomposites during the solidification process. Ultrasonics 2018, 83, 94-102. [CrossRef]

21. Gao, Q.; Wu, S.; Lü, S.; Xiong, X.; Du, R.; An, P. Improvement of particles distribution of in-situ 5 vol \% TiB2 particulates reinforced Al-4.5 Cu alloy matrix composites with ultrasonic vibration treatment. J. Alloys Compd. 2017, 692, 1-9. [CrossRef]

22. Promakhov, V.V.; Khmeleva, M.G.; Zhukov, I.A.; Platov, V.V.; Khrustalyov, A.P.; Vorozhtsov, A.B. The Impact of Particle Reinforcement with Al2O3, TiB2, and TiC and Severe Plastic Deformation Treatment on the Combination of Strength and Electrical Conductivity of Pure Aluminum. Metals 2019, 65, 9.

23. Zhukov, I.A.; Ziatdinov, M.K.; Vorozhtsov, A.B.; Zhukov, A.S.; Vorozhtsov, S.A.; Promakhov, V.V. Self-propagating high-temperature synthesis of $\mathrm{Al}$ and Ti borides. Rus. Phys. J. 2016, 59, 1324-1326. [CrossRef]

24. Zhukov, I.A.; Promakhov, V.V.; Matveev, A.E.; Platov, V.V.; Khrustalev, A.P.; Dubkova, Y.A.; Vorozhtsov, S.A.; Potekaev, A.I. Principles of Structure and Phase Composition Formation in Composite Master Alloys of the Al-Ti-B4C Systems Used for Aluminum Alloy Modification. Rus. Phys. J. 2018, 60, 2025-2031. [CrossRef] 
25. Belov, N.A. Effect of eutectic phases on the fracture behavior of high-strength castable aluminum alloys. Met. Sci. Heat Treat. 1995, 37, 237-242. [CrossRef]

26. Sun, N.; Apelian, D. Friction stir processing of aluminum cast alloys for high performance applications. JOM 2011, 63, 44-50. [CrossRef] 